\title{
Factors Responsible for The Academic Success of African American Females
}

\author{
Jackson de Carvalho, PhD \\ Associate Professor \\ Prairie View A \& M University \\ Prairie View, Texas 77446 \\ United States of America \\ Beverly Spears, PhD \\ Assistant Professor \\ Brailsford College of Arts and Sciences \\ Prairie View A\&M University \\ Prairie View, Texas \\ United States of America
}

\begin{abstract}
African-American females who achieve academic success have been marginalized in research studies, which primarily focus on reporting deficit or negative factors that hinder instead of promoting academic growth. The purpose of this study is to identify environmental, social, and socioeconomic factors that contribute to the academic success of African-American females in secondary and post-secondary institutions. Even though some AfricanAmerican females may experience many different positive or negative factors in their academic environment, continuous high levels of academic support in high school and college are the main predicting factors responsible for their academic success. Irrespective of research that reports psychosocialdeficit and the lack of academic achievedfemales among AfricanAmerican females, they can achieve academic growth, graduate and thrive professionally.
\end{abstract}

Keywords:African American females, teachers, academic success, post-secondary institutions.

\subsection{Introduction}

The success of African-American females in post-secondary education has been consistently increasing despite the adverse environmental, social, and socioeconomic factors imposed on this particular segment of females of the student population. Allen (2015) asserted that teachers with low multicultural competence often develop negative beliefs about the intellectual and academic abilities of their students. Anthony, Kritsonis, and Herrington (2007) identified low expectations from teachers as a major contributor that has plagued "culturally linguistic diverse children, especially African American males" (p. 4). Therefore, if teachers continue to exhibit attitudes of low expectations from their students, theybecome doomed for failure (Delpit, 2012). In order to remove the negative labels placed on AfricanAmerican males, post-secondary institutions need teachers who are multiculturally competent. Removal of labels and the integration of culturally diverse teachers will contribute to an increase in the academic success of student's members of diverse groups (Anthony et al., 2007).

The research studies of DeCarvalho and Colvin (2015) defined academic success as higher levels of Grade Point Average (GPA) and the inclusion of attainment of learning objectives, acquisition of desired skills and competencies, satisfaction with the outcome of obtaining an education, persistence in continuing to attend a post-secondary institution, and success in a career after graduating from college. These definitions integrate the notion of persistence in an attempt to achieve success. In order to persist in achieving academic success and increasing graduation rates in post-secondary institutions, African- American females must continue to persevere towards academic achievement. There is a vast amount of research focusing on the academic failures of African-American females. Moreover, research tends to focus on deficit points of view of African-American culture which exacerbates negative perceptions of potential intellect and behaviors necessary for success (Allen, 2015). Therefore, more research is needed that identifies factors attributing to the academic successes of African- American females, i.e. who have successfully navigated through post-secondary institutions, graduated and moved on to excel professionally.

Despite living in the shadow of years of oppression, historical trauma, and differential treatment relating to race and gender, African American females have shown measured progress in the areas of education and professional endeavors (York, Gibson, and Rankin, 2015). 
Miraculously, the notable increase in success among African American women has occurred in the shadow of continued oppression and persistent discrimination. Surprisingly, these African American women endure many of the same struggles in life that other African American women who are not as successful endure. Oftentimes, these life struggles begin in adolescence. It is at this time that the trajectory of these young African American females is significantly impacted. African American women can either become victims of circumstance and head down a negative road in a life marked by hardship and failures or succeed despite their circumstances(Palmer,Davis, \& Hilton, 2009; Prager, 2011).

\subsection{Review of Literature}

Despite the strides that African American women have made, several research studies (Allen, 2015; Cokley, McClain, Jones, \& Johnson, 2011; Lewis, Butler, Bonner, \& Joubert, 2010) found that African-American females are not achieving in post-secondary institutions at similar rates as Caucasian females. This situation is exacerbated for African American females that are marginalized not only by gender but also by race (Archer-Banks \& Behar-Horenstein, 2012). Within American schools, research has shown that the belief of sex and racial parity is an ambiguous phenomenon for African American females. It is insisted that female students that are not African American exhibit mainstream appropriate behaviors, so a higher priority is placed on the social responses of African American females than females of other races (Morris, 2016).

When African American females exhibit behaviors that do not align with school personnel's notions of femininity, they are chastised for occurrences, such as, "being loud" (Archer-Banks \& Behar-Horenstein, 2012). African American female students are often stereotyped as being "troublemakers" due to being candid and outspoken (Archer-Banks \& Behar-Horenstein, 2012). Due to the biased ways that African American females are portrayed in the media, an effect has been made on ways in which school officials and society perceives them, which subsequently impact their academic performance, retention, and graduation.

According to Thomas (2016), the dropout rate among females ages 16 to 24 is 5.4\%, whereas African American females experienced a rate of $6.5 \%$, followed by White females at $4.1 \%$. These statistics show an evident disparity between African American female students and White female students. A significant disparity is shown in educational statistics among postsecondary education between White and African American female students. According to Thomas (2016), of the $43.2 \%$ of females enrolled in college in 2015, approximately $35.7 \%$ of them were African American and $44.5 \%$ were White. The statisticalfindings of Thomas (2016)show that $65 \%$ of white females enrolled in college earn a bachelor's degree while 11.8\% of African American females hold a bachelor's degree.

These percentages highlight the gap that exists in the educational attainment and achievement of African American female students when compared to their white counterparts. Although the data describe a striking contrast in academic achievement for African- American and Caucasian females, Zhang and Smith (2011) found that African-American women were more likely to exhibit a stronger academic moral belief than Caucasian females. Additionally, the research studies of Stinson (2010) found that African American females still lag behind their Caucasian counterpart in graduation rate. Nevertheless, African-American females were found to havea stronger desire to attend college and were more driven towards academic success despite being unprepared for college. The literature review revealed past research fails to acknowledge or give credence to the historical factors that may have contributed to the success of African Americans women. Gershenson, Holt, \& Papageorge (2016), posited that the literature on minority families is still revised and manipulated to serve the needs and conscience of White America. It is beyond the scope of this paper to provide a detailed account of African American history, however, Delpit (2012) noted that public constructions of the African American female psychosocial and economic structure have historically been colored by an overwhelming assumption of deficit, making it difficult to separate the real effects of poverty and historical, discrimination from the continuation of negative stereotypes. A plausible explanation for some of the self-defeating behaviors of African Americans is found in the seminal research of Jones and Mauer (2013) where they imply that individual and family outcomes generally worsen as the number of risks increase, and concomitantly, resilience fails to take place. In other words, the traumatic experiences of being constantly bombarded with negative barriers to resilience serve as unique obstacles facing African Americans females striving to excel.

The lack of equality between educational attainment and achievement is well documented throughout research (ArcherBanks \& Behar- Horenstein, 2012). To reduce disparity, many researchers have studied a wide variety of factors that contribute to African American females who failed to excel. However, there is a lack of research that examines the success of African American female students, and how variables like gender, racial identity contributes to the African American females' overall school and learning experiences. The intricate nature of racial identity is molded by factors such as history, family dynamics, sociopolitical contexts, and individual characteristics. 
Often, African American females experience developmental complications as a result of difficulty coping with negative group stereotypes linked to society's flawed perceptions.

\subsection{Problem Definition}

Creating alternative academic solutions for African American female students who are not learning during the customary school day has become an issue for educators and community members. Concern regarding this issue has grown to a national level due to the achievement gap between African American students and their white peers. Failure to obtain a post-secondary education, for African American females, increases the likelihood of unemployment, lowwage work, and incarceration (Crenshaw, 2012). There may be additional challenges that this population of African American females' face. According to Heitzeg (2016), these struggles may include invisibility and speaking one's voice. The invisibility and silence can be observed as obligatory to acquiring entry into the dominating patriarchy (Heitzeg, 2016). To assure that this population of African American female students becomes involved and continues to discover their voice, practitioners must recognize their needs and provide the supports needed to aid in their academic success.

Although, African American female students face manyhardships that often hinder their academic achievement, the existing research literature, public policy debates, and data neglect to focus on the extent to which females encounter risks that are akin to and different from those faced by females of other ethnicities. The perils that African American females face are often overlooked by policymakers and researchers. There has been a lack of studies that examine the relationship between African American female students' academic success and the factors that contribute to it (ArcherBanks \& Behar- Horenstein, 2012; Price, 2015; Smith-Evans \& George, 2014).As stated by Jones and Mauer (2013) "If America is to continue to be a strong nation, it must make its programs and policies relative to the needs of the poorest citizens" (p. 64). Therefore, the overarching question for this study becomes, What can we learn from successful African Americanfemales that can be translated into intervention or programs that can help other children and families facing similar risks?

\subsection{Media's Role in African American Females' Perceptions}

There are many reasons to find frustration when reviewing the plights of African American female students. Some blame can be placed on the media "as girls have difficulty developing a positive sense of self because of the media portrayals of young women as sexual objects with a singular emphasis on appearance" (Manago, Brown, \& Leaper, 2009, p. 750). Researchers have questioned the part that the media plays in the self-perception of African American females (Gordon, 2008). The images of African American females in the media are often hypersexualized, have little to no social skills, a host of other negative portrayals, and are placed in the movies distributed to American society (Archer-Banks \& Behar-Horenstein, 2012). Morris(2016) describes ways that media interpret "what beautiful is" and the effects this has on African American females' self-perception and academic abilities. As African American females begin to try to figure out who they are, they continuously compare themselves to the images they see daily.

The media has not done an excellent job of portraying African American women as strong, intelligent, and talented. Instead, they are looked at for their outward appearance (Morris, 2016). This imbalance has given African American females a skewed perception of who they are supposed to be (Morris, 2016). Archer-Banks and Behar-Horenstein (2012) argue that when African American female students attempt to fit into White mainstream ideals and values, they use these poorly described examples as the criterion for their ability to navigate their challenges within a school. Morris (2016) contends that these negative images are also used by school officials to determine how to interact with African American female students, which has created disadvantages for this population of students.

According to Jones and Mauer (2013), African American females, are habitually believed to use "obnoxious and loud behaviors" in social interactions. This perception often results in the school personnel taking up more time addressing social behaviors rather than focus on students' academic success. It is paramount to find a way to positively alter African American female students' perception of self and their academic achievement.It is the responsibility of all in the community to help the changes and constructs of self-identity that adolescent females face (Tillman, 2009). This responsibility should be shouldered by the schools, community members, leaders, teachers, and organizations to provide resources for these females to enable them to reach their infinite human potential. African American females must findsuccess in those around them and with themselves (Lipsky \& Johnson, 2010).

\subsection{Academic Identity}

Research implies that African American female students' beliefs about race and self-awareness correlate with (a) their attitudes about the value of education, (b) their academic attainment, and (c) their social and educational development (Archer-Banks \& Behar-Horenstein, 2012). 
As a result, African American females embrace forms of knowledge available in their communities and reject the forms available within schools that appear irrelevant and more difficult to apply in their lives (Archer-Banks \& BeharHorenstein, 2012). African American female students who do not find their education to line up with their future goals and aspirations demonstrate less effort and engagement in school activities (Price, 2015). Contrarily, African America female students who exhibit belief in their academic abilities and recognize the school as an appropriate means to achieving their goals may become proficient at maneuvering the inequalities faced in the attainment of their academic success.

Researchers often conceptualize the behaviors of African American or Hispanics with the characterization of personsin-settings; however, this may not hold true to the way these students are referenced by their peers or themselves (Archer-Banks \& Behar-Horenstein, 2012). Tillman (2009) asserted, "The idea that a racial category connotes ascribable characteristics of individuals in the category is logically and empirically unsupportable" (p. 94). Personal experiences through interactions with peers and teachers aid in the development of sociocultural constructions of self and racial identity. Tillman (2009) advanced the notion that the situationby-situation assessment of self-worth that is experienced by daily interactions with others at school is negated by the idea that identity is an all-or-none premise. Thus, the understanding of academic identity is regularly modified from one's vantage point in classrooms. African American female students can maintain the "integrity of their social identity" by being offered opportunities that allow them to engage proactively in sociocultural communication with peers, teachers, and through curriculum (ArcherBanks \& Behar-Horenstein, 2012). Hence, the evolution of identity is continuous.

African American female students are beset by racial defaming contexts and instructional practices within educational institutions that result in achievement and learning gaps. The belief that there is an achievement gap is ultimately due to the failure to acknowledge the previous statement. The students that attain academic achievement are those that buy into the beliefs of the school culture (Archer-Banks \& Behar-Horenstein, 2012). Scott (2009) conducted a study that focused on teacher responsiveness to a group of African American students in middle school. The results of this study found that teachers stress the dissemination of logical and analytical information. This method of instruction was counterproductive for students that favored learning experiences that were personal and relational. The students showed disengagement as a result of teachers' punitive teaching style coupled with the instructional focus. Scott's study brings awareness to the disconnection that occurs even when educators put forth their best effort to teach African American students. Scott's research also depicts the results of counterproductive pedagogy on African American student achievement.

African American female students must develop coping skills to offset the mental threats embedded in the cultural practices within the school environment that are uninspiring and embedded in the history of racism that still must be countered (Archer-Banks \& Behar-Horenstein, 2012; Cunningham, Corprew, \& Becker, 2009; Tillman, 2009). The intricate nature of racial identity is molded by factors such as history, family dynamics, sociopolitical contexts, and individual characteristics. According to research, a person becomes aware of their identity and begin the exploration of it in early middle school (Archer-Banks \& Behar-Horenstein, 2012; Price, 2015). African American females experience developmental complications as a result of difficulty coping with negative group stereotypes linked to society's flawed perceptions. As African American female students align themselves as high academic achievers, they may avoid activities and affiliations to their racial group as a result of the internalization of the negative perceptions (ArcherBanks \& Behar-Horenstein, 2012).

One may often find that some African American females compromise their academic achievement as allegiance to their African American peers. During high school, African American female students become more aware of their racial identity (Archer-Banks \& Behar-Horenstein, 2012). The identities that African American female students have adopted, by this time in their lives, have a significant influence on their academic achievement and choices (Price, 2015). According to Archer-Banks and Behar-Horenstein (2012), African American females' beliefs about race and self, correlate with their social and educational development, and their perceptions of the relationship of their reality and the value education have within it.

\subsection{Achievement Gap}

A primary reason as to why African American female students fall behind their peers of other races is due to their respective schools' inability to provide adequate courses, supports, and resources (Bryant, 2015). Adequatecourseworksupports and educational resources are vital to upgrading educational experiences and the improvement of learning. Without the proper resources needed, many African American female students are offered fewer opportunities to challenge themselves academically (Smith-Evans \& George, 2014). A phenomenological research study conducted by Price's (2015) suggestedthat African American and White girls enter school with more similarities than differences. 
The authors also concluded that another reason for African American females to lag behind in academic achievement may be attributed to teachers reinforcing social behavior for African American females and academic behavior for White females. Oftentimes, teachers would ask the African American female students to help others with non-academic tasks and white females to assist with academic assignments. Prices (2015) also found that teachers often described African American females as performing to their ability academically and their white counterparts as not working to their full potential. Additionally, Morris (2016) found that African American females reported feelings of being challenged less academically. According to Smith-Evans and George (2014), when challenged less academically, these students are at greater risk of not being able to excel academically and subsequently not being prepared for a highpaying career. African American female students have become normalized to the unequal treatment they are subjected to daily within the education system that is supposed to provide equal education to all students.

The research study of Gilliam, Maupin, and Reyes (2016) reveals clues as to why disparities may exist in education for African American female students. This research indicates that disparities may exist due to implicit bias (Gilliam, Maupin, \& Reyes 2016). Gilliam, Maupin, and Reyes (2016) define implicit bias by the stereotypes and attitudes that affect our understanding, decisions, and actions unconsciously. For example, these unconscious stereotypes take form in the classroom when African American female students are chosen to be workers (i.e., office runners) instead of leaders (group leads). When these unconscious stereotypes are held by teachers, it results in lower expectations for African American female students (Gershenson, Holt, \& Papageorge, 2016). The Yale study indicates that this bias occurs earlier in education than previously thought and is present in both white and black teacher behaviors (Gilliam et al., 2016). Thus, if African American female students are not properly developed inside schools, external agencies/programs are required to aid African American female students in the attainment of equitable education opportunities.

The U.S. Supreme Court outlined the key components of an educational institution's operations that courts should explore when choosing whether the school system has disposed of the remnants of segregated education (Smith-Evans \& George, 2014). These variables, such as qualified instructors, extracurricular activities, and thorough curriculum, are critical to the achievement of African American female students today (Smith-Evans \& George, 2014). Although the goal is to ensure that all the variables are applied, many school officials lack the skills required to meet the needs of these students, resulting in African American girls struggling to achieve academically. According to Morris (2016), the difference in educational outcomes can stem from not only school operations, but also the neighborhood located within. Social factors in the community, home, and school influences youth development (Bryant, 2015). In essence, a framework that addresses both systematic and personal influences are required for an extensive analysis of African American female students' academic achievement. The development of effective practices and policies are contingent upon the understanding of these factors (Gilliam et al., 2016).

\subsection{Bridging the Gap}

There is a paucity of literature that specifically addresses the needs of African American adolescent female strugglingto succeed academically, particularly when looking at the varied psychosocial factors that influence repetitive positive behaviors (Morris, 2016).In an effort to bridge the gap between the existing literature and the needs of academically engaged adolescent females, it is imperative to gather information from African American female populations of similar environmental backgrounds who have been resilient and found ways to buffer themselves from the deleterious effects of cultural and environmental stressors (Smith-Evans \& George, 2014).

Though there is a growing population of African American females who dropout of college and settle for less, there is also measured progress in the areas of education, professional endeavors, political participation, and financial independence within the same demographic (Gilliam et al., 2016). There is limited information about programs that successfully empower African American women to succeed academically. Nevertheless, in an attempt to prevent and intervene with at-risk youth, teen pregnancy, school dropouts, and unemployment, the concept of adult mentoring has become vital (Munson, 2010). Simões and Alarcão (2014) defined mentors as a person who cares for, listens to, shares life experiences, and guides one another, especially a youth requiring assistance. Agencies that serve youth seek out adults to become mentors in their community to guide youth down a positive life track.

According to Simões and Alarcão (2014), the mentoring programs that are deemed most successful are those that extend frequent long-term contact between the adult and the student mentee. The number of mentoring programs for African American female students has increased across the United States. Munson's (2010) study compared students that participated in a mentoring program to those that did not. It was found that the Big Brothers Big Sisters mentors that met with their mentee consistently over the span of one year saw that youth were $52 \%$ less likely to miss a day of school and $46 \%$ less likely to use drugs. 
The results of the study also indicated that over time the communication skills of youth participating in these programs increased with their mentors from building a trusting relationship (Munson, 2010). Research shows that positive effects on social, emotional, and academic performance are made through adult mentoring with African American female students (Morris, 2016; Simões\&Alarcão, 2014). Females rather than males tend to become more self-reliant and have more of a positive outlook on life (Munson, 2010). The school environment alone is not the only means to help these beliefs emerge but also with the assistance of positive mentoring relationships to further the notion (Munson, 2010).

There are three main mentoring perspectives found in the research study literature-psychological, social and biological (Simões\&Alarcão, 2014). The psychological perspective describes how the mentor undeniably increase resilience among African American females by acting as an "external regulator" as their abilities and strengths are used until theyprogressivelyinternalize them (Munson, 2010). The social perspective explains that as mentors expose the youth to their personal and professional environments, youth obtain a broader environment (Munson, 2010). The biological perspective examines the activation of complicated neurobiological wiring that is associated with attachment, learning, memory, and reward (Munson, 2010). The youth begin to mimic their mentor's behaviors due to the repetitive imitation of behaviors and cognitive strategies the mentor displays during their time spent with the youth (Southwick et al., 2006). New neuronal connections and branches are made because the behaviors allow the brain to become activated (Simões\&Alarcão, 2014). The mentor can focus on how a mentoring relationship should be approached if he or she understands the developmental effects of adult mentoring on youth, especially on African American female students (Munson, 2010).

Mentoring relationships become increasingly important as the phenomenon of investing expertise and personal growth in the U.S. where society has become professional, specialized, and competitive to be successful (Munson, 2010). Adults that can share their life experiences with youth are needed. They are essential in the guidance of youth so that they can envision what they can become in life (Munson, 2010). Adult mentors are needed to help youth navigate career motivation, avoidance of harmful relationships, the building of self-esteem, and overall academic achievement (Morris, 2016). Mentors can assist in providing African American female students access to the tools needed to create better future outcomes.

African American female students require multiple outlets to aid in their academic success. Many of these outlets, including mentoring, are done after school hours. Next is a review of the importance of extracurricular activities on the academic achievement of African American female students (Simões\&Alarcão, 2014).

\subsection{Implications for Practice}

This study has clear implications for educators as it reinforces the widely held belief that schools and communities must form strong coalitions to enhance student achievement. Communities who fail to maintain environments conducive to learning need assistance and guidance because learning starts at home. It is imperative that educators and policymakers be aware of the factors of youth mentorship programs, particularly programs that serve African American female students that aid in academic success. These factors are essential to the lives of the African American female students served and to additional stakeholders. Research consistently finds that a positive learning environment has a powerful impact on student achievement. Positive effects include significantly improved school behavior and improvement in general educational performance. Youth mentorship programs aid African American female students as they cultivate the necessary skills required to be academically successful. Educators, researchers, parents, administrators, and public officials, who are interested in acquiring tools to redirect and affect the lives of African American female students can utilize the information presented in this study.

Finally, the findings of this study can inform the development of programs designed to empower African American female students to become academically and professionally successful. It is also recommended that educational institutions will utilize the current study to aid in the daily education of African American female students, by recognizing and applying the tools they need to succeed. The findings of the study are intended to offer educators knowledge on the participants described experiences to gain a deeper understanding of their needs within leadership development programs and educational institutions. To provide quality programming for African American female students, educators and practitioners may utilize the information presented in this study to aid in the strengthening of their programs. We hope that all African American female students will be provided the opportunity to grow and develop leadership skills that will aid in their future academic and professional success. 


\section{References}

Allen, Q. (2015). 'I'm trying to get my A': Black male achievers talk about race, school,and achievement. Urban Review, 47(1), 209-231. doi: 10.1007/s 11256-014-0315-4

Anthony, T. D., Kritsonis, W. A., \& Herrington D. (2007). National cry for help: Psychosocial issues as they relate to education; a realistic approach to understanding and coping with the African males. The Lamar University Electronic Joumal of Student Research, 4(3).

Archer-Banks, D. A., \& Behar-Horenstein, L. S. (2012). Ogbu Revisited: Unpacking High Achieving African American Girls High School Experiences. Urban Education,47(1), 198-223. doi:10.1177/0042085911427739

Bryant, R. T., \& Center for Law and Social Policy, (. (2015). College Preparation for African American Students: Gaps in the High School Educational Experience.

Cokley, K., McClain, S., Jones, M., \& Johnson, S. (2011). A preliminary investigation of academicdisidentification, racial identity, and academic achievement among African-American adolescents. High School Journal, 95(2), 54-68.

Crenshaw, K. (2012). Black Girls Matter: Pushed Out, Overpoliced And Underprotected. African American Policy Forum, 1-53. Retrieved September 9, 2016, from https://static1.squarespace.com/static/53f20d90e4b0b80451158d8c/t/54d2d37ce4b024b4 1443b0ba/1423102844010/BlackGirlsMatterReport.pdf.

Cunningham, M., Corprew, C. I., \& Becker, J. E. (2009). Associations of Future Expectations, Negative Friends, and Academic Achievement in High-Achieving African American Adolescents. Urban Education, 44(3), 280-296

deCarvalho, J. N. \&Colvin, A. D. (2015). Emotional intelligence and academic success among low-income college students. International Journal of Education and Social Science. 2(3)35-42

Delpit, L. D. (2012). Multiplication is for white people: raising expectations for other people 's children. New York: New Press

Gershenson, S., Holt, S. B., \& Papageorge, N. W. (2016). Who believes in me? The effect of student-teacher demographic match on teacher expectations. Economics of Education Review, 52, 209-224.

Gilliam, W., Maupin, A., \& Reyes, C. (2016). Do implicit biases regarding sex and race relateto behavior expectation and recommendations of preschool expulsions and suspensions? New Haven, CT: Yale University Child Study Center.

Heitzeg, N. A. (2016). The school-to-prison pipeline: education, discipline and racialized double standards. Santa Barbara, CA: Praeger.

Jones, S., \& Mauer, M. (2013). Race to incarcerate: a graphic retelling. New York: The New Press

Lewis, C. W., Butler, B. R., Bonner, F. A., \& Joubert, M. (2010). African-American male discipline patterns and school district responses resulting impact on academic achievement: Implications for urban educators and policymakers. Journal of African-American Males in Education, 1(1), 7-25

Lipsky, J., \& Johnson, K. (2010). Mentoring at-risk youth: Improving academic achievement in middle school students. Nonpartisan Education Review, 5(1), 235-242

Manago, A. M, Brown, C. S., \& Leaper, C. (2009). Feminist identity among latina adolescents. Journal of Adolescent Research, 24 (6), 750-776.

Morris, M. (2016). Pushout: The Criminalization of Black Girls in Schools. New York, NY: The New Press

Munson, C.A. (2010). Leadership experiences of adolescent girls in a girl scouts after school program: a phenomenological approach (Dissertation). Retrieved from ProQuest Dissertations and Theses database.

Palmer, R. T., Davis, R. J., \& Hilton, A. A. (2009). Exploring challenges that threaten to impede the academic success of academically underprepared black males at an HBCU. Journal of College Student Development, 50(4), 429445.

Palmer, R. T., \&Maramba, D. C. (2011). African-American male achievement: Using a tenet of critical theory to explain the African-American male achievement disparity. Education and Urban Society, 43(4), 431-450. doi: $10.1177 / 0013124510380715$

Prager, K. (2011). Policy notes: News from the ETS policy information center. ETS Policy Information Center, 19(3), 1-16. Retrieved from: https://www.ets.org/Media/Research/pdf/PIC-PNV19n3.pdf

Price, V. (2015). The Quest for Success: A Phenomenological Study Aimed at Understanding the Experiences of Successful African American Females in High School. Educational Administration: Theses, Dissertations, and Student Research. Paper 249.

Scott, W. R. (2009). Teachers' responsiveness to the learning needs of a select group of African American middle school students. (Unpublished doctoral dissertation). University of Florida, Gainesville. 
Simões, F., \&Alarcão, M. (2014). Mentors and Teachers: Testing the effectiveness of simultaneous roles on school performance from a basic psychological need's satisfaction perspective. Instructional Science, 42(3), 465-483

Smith-Evans, L., \& George, J. (2014). Unlocking Opportunity for African American Girls. Women's National Law Center. Retrieved from:

https://www.nwlc.org/sites/default/files/pdfs/unlocking_opportunity_for_african_america n_girls_report.pdf

Stinson, D. (2011). When the 'burden of acting white' is not a burden: School success and African-American male students. The Urban Review, 43(1), 43-65. doi:10.1007/sl 1256- 009- 0145-y

Tillman, L. C. (Ed.). (2009). The sage handbook of African American education. Thousand Oaks, CA: SAGE Publications

Thomas, S. L. (2016). A phenomenological exploration of the experiences of students enrolled in school-wide college readiness programs (Order No. 3739342). Available from ProQuest Dissertations \& Theses A\&I; ProQuest Dissertations \& Theses Global. (1748613953). Retrieved from https://search.proquest.com/docview/1748613953?accountid=26417

York, T. T., Gibson, C., \& Rankin, S. (2015). Defining and measuring academic success. Practical Assessment Research \& Evaluation, 20(5), 1 -20.

Zhang, P., \& Smith, W. L. (2011). From high school to college: The transition experiences of Black and White students. Journal of Black Studies, 42(5), 828- 845. doi: 10.1177/0021934710376171 